Afric

ArXiv

Article title: Assessing the state of forensic support to criminal investigations in Ghana: A case study in the Greater Accra Region

Authors: Yahaya Sumara Sulley[1], Lydia Quansah[2]

Affiliations: University for Development Studies[1]

Orcid ids: 0000-0002-0411-801X[1], 0000-0003-4883-5990[2]

Contact e-mail: araman2016@hotmail.com

License information: This work has been published open access under Creative Commons Attribution License http://creativecommons.org/licenses/by/4.0/, which permits unrestricted use, distribution, and reproduction in any medium, provided the original work is properly cited. Conditions, terms of use and publishing policy can be found at https://www.scienceopen.com/.

Preprint statement: This article is a preprint and has not been peer-reviewed, under consideration and submitted to AfricArXiv Preprints for open peer review.

DOI: $10.14293 / 111.000 / 000011 . v 1$

Preprint first posted online: 20 September 2020

Keywords: criminal investigations, criminal justice system, forensics science, forensic support, fundamental human rights, Ghana, Justice delivery 


\title{
ASSESSING THE STATE OF FORENSIC SUPPORT TO CRIMINAL INVESTIGATIONS IN GHANA: A CASE STUDY IN THE GREATER ACCRA REGION OF GHANA
}

\begin{abstract}
Forensic science applications in criminal investigation are very profound to crime resolution. However, there is a wide gap between the application of specialist skills and public knowledge and awareness of forensic science in criminal investigations and it has generated complex practical problems in justice delivery in Ghana. The study attempts to assess the state of forensic support to criminal investigations by accessing public knowledge and perception of forensic science in Ghana. To this account, an elaborate and tortuous survey was conducted using 200 consented respondents in selected neighborhoods in Accra based on homogeneity, population density, economic or industrial activities, and the nature of crime and police activities. The survey included face to face interviews, questionnaire responding, and random phone calls. The final data which was subjected to a simple linear regression model were analyzed with STATA 13. The study revealed that indeed, forensic science in Ghana has "gone dark" as 165(82.5\%) who had a formal education of various levels had very limited knowledge about forensic science and procedures. The majority of the respondents $179(89.5 \%)$ had no idea about forensics and for that matter lacked awareness of forensics in Ghana before the research while the state of forensics in Ghana was rated on the scale of good (10.5\%), bad (81.5\%) and very bad (8\%) out of the 200 respondents with the respondent level of education, perception, knowledge, and awareness of forensic science and support significantly impacting the wellbeing of the research. The findings of this study call for government and respective stakeholders and policymakers of various institutions, and the adversarial system of Ghana to prioritize the need for forensic science. This is to support criminal investigations to assure the Ghanaian citizens of their safety, security, and fundamental Human rights to justice.
\end{abstract}

Keywords: criminal investigations, criminal justice system, forensics science, forensic support, fundamental human rights, Ghana, Justice delivery 


\section{INTRODUCTION}

Forensic science is a branch of science (1) that uses scientific principles to investigate crime and solve matters at the court of law (2). The use of forensics to solve crimes has demonstrated magnificent success worldwide and has caused a great revolution to justice systems worldwide (1). The world presents a very great population of advocates of the use of forensics in solving crimes (3). Criminal activities are inevitable situations in our societies which can be explained based on different perspectives. Previously in Ghana, there had been different ways of solving crimes which were mainly orthodox. However, the year 1921 saw the creation of The Criminal Investigations Department (CID) of the Ghana Police Service (GPS) to grant technical support and improve crime solving through scientific approaches $(4,5)$.

The CID of Ghana operates a crime (forensic) laboratory $(6,7)$ and in addition to that, the department has a fingerprint unit located at the CID Headquarters which has been fully operational since 1922 (7). The Forensic Science Laboratory (FSL) is located at "Kawo Kudi" in Accra and it is the only forensic laboratory serving all the 651 police stations (5) across the 16 regions of Ghana. The CID laboratory is an ultramodern forensic laboratory, with five different units making it the first of its kind in West Africa (8).

Major findings from the Ghana police service and available literature informs us about the rate at which crimes have increased in Ghana. It, however, appears that the usual method of investigation by the GPS is seen by most citizens to be interrogating and interviewing victims, suspects, or witnesses at the crime scene and apprehending and incarcerating suspects without forensic procedures being applied (9). It is well noted that in rape case situations, there is some form of forensics however it is mostly depending on the status of victims and suspects for the case to be given adequate attention. In 2018, the exoneration of a convicted suspect, Mr. Emmanuel Asante 
through a further forensic analysis at the FSL after he served 12 out of 15 years of his sentence for wrongfully being accused of raping and impregnating a student in Tamale (8) in 2006 informed the public about the importance of forensic investigation to justice delivery in Ghana.

Notwithstanding, there is limited scholarly research on forensic science to ascertain the state of forensic support to criminal investigations in Ghana hence the objective of the study was to assess public knowledge and perception of forensic science. It also sorts to ascertain from respondents their view of the state of forensic support to criminal investigations in Ghana. The study goes further to ask questions about the factors that influence people's knowledge and perception of forensic science in Ghana while discussing the emphasis of formal education on people's knowledge about forensic science.

\section{METHODOLOGY}

\section{Study area}

The research selected the Greater Accra region as the study area and specifically targeted Accra, Ashaiman, Tema, and Kpone Katamanso due to diversity, homogeneity, economic and industrial activities, and the nature of crime and police activities in these areas.

\section{Study design, population size, and data collection}

The study started after semi-structured interviews were conducted with personnel at the Forensic Science Laboratory (FSL) to acquire accurate information. The study considered 200 randomly selected respondents for an interview through a random survey with a questionnaire and random phone calls for five months. The Slovin's formula mathematically states that $n=n /\left(1+n e^{2}\right)$. The sample size is represented by (n), the target population is also represented by (n), and (e) shows 
the degree of freedom with a margin error of 0.05 indicating a confidence level of $95 \%(11)$, hence it was used to calculate the size of the study population.

\section{Ethical consideration}

Ethical consideration was granted by the CID Headquarters of Ghana to elicit accurate information from personnel at the FSL and the general public.

\section{Data processing and analysis}

The qualitative data was analyzed and transcribed while quantitative data was coded and analyzed and presented in graphs and tables with Microsoft office 16 software. A simple linear regression analysis was performed to understand the relationship between factors that influenced knowledge and perception about forensic science with (STATA (13)) computer statistical software package.

\section{RESULTS}

\section{Socio-demographic characteristics and its influence on respondents}

The sociodemographic characteristics of respondents had a great impact on the data gathered throughout the survey. Throughout the interview process, it was realized that respondents from the selected neighborhoods had different mindsets based on their present location at the time of study which influenced their perspectives towards the GPS. Respondents who participated in the study fell within ages ranging from 11-60 years with a male majority of $123(61.50 \%)$ and the remaining being females. The study made strides to avoid ethnicity or tribal biases by collecting responses

from different ethnicities across Ghana including transborder tribes such as Hausa, Yoruba, Kotokoli, Gao, and Zabarma. Devoid of stereotype and discrimination based on previous 
experiences or criminal records or history, respondents from every religion were taken into consideration and it was recorded that majority of respondents were Christians 136(68\%) followed by $44(22 \%)$ Muslims while 20(10\%) were considered as those from other religions.

The level of exposure was measured by how far respondents have reached in terms of education or their career experience and as expected the responses came from respondents across all levels and forms of education as $165(82 \%)$ were found to have attained formal education either at the basic level or higher-level education while 35(17.50) had been either engaged in informal education i.e. (apprenticeship) or other occupations. The extent of neighborhood disorder was measured considering what respondents perceived about their neighborhood. Items used to identify neighborhood disorder included rates of vandalism, state of abandoned houses, and state of delinquent gangs, state of drug dealing and drug abuse, and nature of the neighborhood (presence

or absence of street lights, slums, and well-demarcated streets) as a whole. A few 12(6\%) respondents who lived in more secured locations gave good accounts about the GPS and this was based on their sense of security, past or personal experiences with personnel in GPS, and their place of residence. Aside from the positive remarks about the GPS, only 11(5.5\%) respondents reported having ever contacted the police for forensic support. The remaining 189(94.5\%) respondents did not hesitate to regard criminal investigations conducted by GPS as deficient of forensic procedures in their neighborhoods as shown in (Table 3).

\section{Public knowledge and perception of forensic science in Ghana}

The data (Table 2) shows that forensic science is very unpopular in the country because about $179(89.5 \%)$ of the respondents were not aware or had no knowledge about forensic science and procedures until the researcher's brief introduction before the interview. This category of the 
research population was not even aware that forensic procedures included assessing fingerprint through their biometric ID cards for forensic analysis in crime labs. For those who had an idea or knowledge about forensics, most of them had their source of knowledge mainly from Television series and documentaries with only a few acquiring the knowledge from academic papers and classroom or formal education. It was however realized that, across the data, respondent's area of interest in terms of education had a great influence on their understanding of the subject of research previously or just before the interview. Upon carefully analyzing this category of the population, $34(17 \%)$ respondents were identified as either practicing or interested in law programs. The results of the study showed that 3 respondents had a fair knowledge about forensics while the remaining 31 had limited or no idea. On the other hand, 77(38.5\%) respondents were either involved or interested in science-related programs and the majority of these respondents were identified as undergraduates or doing postgraduate studies or research. It was revealed that 38 out of the 77 respondents had a fair knowledge about forensic science and its importance in crime-solving either from movies, documentaries, or from scholarly literature while 39 had either limited or no knowledge from similar sources.

Specific questions were used to ascertain the respondent's perceptions about the GPS. Without hesitation, all the 200(100\%) respondents answered positively to the question "Are you aware that GPS is responsible for law enforcement in Ghana?". Even though all respondents were aware of the great responsibility shouldered by the GPS, 188(94\%) had a bad perception about GPS and most of the responses were allegedly attributed to prejudice, ineffectiveness caused by bribery and corruption, poor level of education in the police department, poor police training and other issues regarding institutional trust. Out of the total sampled population, 141(70.5\%) respondent's answers were greatly influenced by the bad perception they had about GPS at the time of the study. The 
remaining 59(29.5\%) respondents were made up of the 47 with negative perception about GPS alongside 12 of those with positive perception about the GPS. This group were however optimistic about the fact that things will change for the better in one way or the other with time hence they had no reason to respond based on their negative perception about GPS.

Even though most respondents $123(61.5 \%)$ had little or no knowledge about forensic, in the course of the study they were able to tell and distinguish normal police investigative procedures from forensic procedures and make judgments to create a distinction based on their experiences and encounters with criminal investigations conducted by GPS as shown (Table 1). Respondents upon realizing the need for prioritizing forensic science in the country, most of them were generally impressed about forensics science and linked it with the crime-solving situation in Ghana. All respondents agreed that forensic science is a crime-solving tool and forensic evidence can help prevent delay in justice delivery and justice miscarriage. However, the study identified 26(13\%) of the selected population agreeing that forensic science does not or will not always provide positive results as they kept emphasizing professionalism, privacy, and ethical issues relating to the handling of evidence samples and manipulation of results. Most of the respondents linked their responses to the fact that there are numerous unsolved crimes in Ghana which will continue to remain the same simply because of some "untouchables" (12-14) in society. Based on respondent's own experiences, perspectives, and education acquired during the study, respondents made their general impressions about the state of forensic support to criminal investigations in Ghana. Their ratings were based on a liked scale as follows; good 21(10\%), bad 163(82\%), and very bad 16(8\%) (Figure 1). 
Table 1: Respondents perception about forensics science

\begin{tabular}{llll}
\hline Bad Perception & Frequency & Percentage \% & Cumm. \\
\hline Yes & 141 & 70.50 & 70.50 \\
No & 59 & 29.50 & 100.00 \\
Total & 200 & 100.00 & \\
\hline
\end{tabular}

Table 2: Respondents knowledge and awareness of forensics before the interview

\begin{tabular}{llll}
\hline Forensic awareness & Frequency & Percentage \% & Cumm. \\
\hline Yes & 21 & 10.50 & 10.50 \\
No & 179 & 89.50 & 100.00 \\
Total & 200 & 100.00 & \\
\hline
\end{tabular}

Table 3: Respondents view on criminal investigative procedures

\begin{tabular}{llll}
\hline Forensic procedures & Frequency & Percentage \% & Cumm. \\
\hline Yes & 11 & 11.50 & 11.50 \\
No & 189 & 94.50 & 100.00 \\
Total & 200 & 100.00 & \\
\hline
\end{tabular}

The state of forensic support to criminal investigation in Ghana

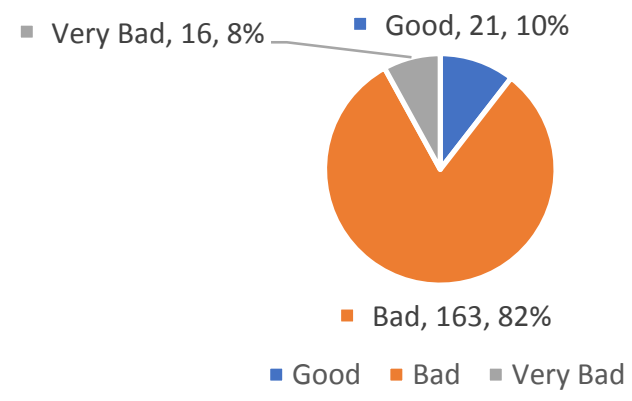

Figure 1: Respondents general rating on the state of forensic support to criminal investigations in Ghana

Source: Field survey, January 2019

Simple linear regression analysis

Factors affecting knowledge and perception of forensic science and support in Ghana

The data gathered across the selected neighbourhoods was used to understand the social reality by subjecting the qualitative data to a simple linear regression analysis as shown (Tables. 4,5$)$ based 
on the model represented with the formula; $y=\beta_{\mathrm{O}}+\beta_{1} X+\varepsilon$ where; $\mathrm{y}$ is the predicted value of the dependent variable (y) for any given independent value. B0 is the intercept which represents the predicted value of $\mathrm{y}$ when $\mathrm{x}$ is $0 . \mathrm{B} 1$ is the regression coefficient which explains how much we expect $\mathrm{y}$ to change as $\mathrm{x}$ increases. $\mathrm{X}$ is the independent variable that is expected to be influencing $\mathrm{y}$ while $\varepsilon$ is the error or measure of the variation of the estimate.

Responses were coded as variables that influenced each other and were explained based on how strong the relationship between the dependant variables and the independent variables were. The analysis conducted gave estimates of how the perception and knowledge of forensic science (dependent variables) change as the independent variables change with time and how it influenced the state of forensic science in Ghana. The analysis was measured based on a good explanatory power of; (Prob > F = 0.000) with R-squared of $83.65 \%$ and (Prob > F = 0.000) with R-squared of $23.13 \%$ for public perception and their knowledge about forensic science respectively.

Table 4: Public perceptions about forensic science

\begin{tabular}{llll} 
Variable & Coefficient & Std. Err & $\mathbf{P}>|\mathbf{t}|$ \\
\hline Forensic support & 0.4964937 & 0.1051249 & $0.000^{* * *}$ \\
Education & 0.0139064 & 0.0188191 & $0.016^{* *}$ \\
Perception about GPS & 0.2119617 & 0.1078402 & $0.051^{* *}$ \\
Forensic knowledge & 0.2326804 & 0.0802048 & $0.004^{* * *}$ \\
Age & -0.0025261 & 0.0028408 & 0.375 \\
Constants & -0.1725395 & 0.0866967 & 0.000 \\
\hline
\end{tabular}

Number of observations = 200; Prob $>$ F = 0.000; R-squared $=0.2313$ 
Table 5: Public knowledge of forensic science in Ghana

$\begin{array}{llll}\text { Variable } & \text { Coefficients } & \text { Std. Err } & P>|t|\end{array}$

$\begin{array}{llll}\text { Level of education } & 0.069713 & 0.0152084 & 0.000^{* * *}\end{array}$

$\begin{array}{llll}\text { Gender } & -0.0833836 & 0.0314951 & 0.009\end{array}$

$\begin{array}{llll}\text { Religion } & -0.0408629 & 0.072541 & 0.574\end{array}$

$\begin{array}{llll}\text { Ethnicity } & -0.0110485 & 0.0134383 & 0.412\end{array}$

$\begin{array}{llll}\text { Perception (forensics) } & 0.0560321 & 0.0222873 & 0.013^{* *}\end{array}$

$\begin{array}{llll}\text { Forensic support } & 0.845126 & 0.0513649 & 0.000^{* * *}\end{array}$

$\begin{array}{llll}\text { Source of knowledge } & 0.1204083 & 0.0077182 & 0.000 * * *\end{array}$

$\begin{array}{llll}\text { Perception (GPS) } & 0.1223348 & 0.0161785 & 0.000 * * *\end{array}$

$\begin{array}{llll}\text { Constant } & 0.0757172 & 0.0962525 & 0.432\end{array}$

Number of observations $=200 ;$ Prob $>$ F $=0.000 ;$ R-squared $=0.8365$

Note: $* * *, * *$ and $*$ implies significance at $1 \%, 5 \%$, and $10 \%$, respectively.

Prob > F - The F-value is the Mean Square Model (2385.93019) divided by the Mean Square Residual (51.0963039), yielding $F=46.69$. The $p$-value associated with this $F$ value and how small it is tending to answer the question "Do the independent variables reliably predict the dependent variable?" while R-Squared measures the overall strength of association.

Source: Field survey, 2019 


\section{DISCUSSION}

To develop and maintain progressiveness in terms of solving crime, the study attempted a bigger problem by breaking it into smaller pieces with intentions to scale up in the future. The study based on prior knowledge acquired based on surveys and interactions with key stakeholders to select the use of forensic science to solve crimes and in Ghana as an imminent solution to administer justice. Responses collected across the total target population explained respondents understanding about the reality surrounding them indicating that they are the right people to solicit information from (15). The study's null hypothesis assumed that there was no significant relationship between respondent's general perception or knowledge of forensic science and other independent variables. However, based on the analysis in (Table 4,5) the null hypothesis can be ignored based on the levels of significance recorded at $1 \%$ and $5 \%$ with key independent variables.

Upon analyzing the data in (Table 4) the perception of respondents tends to be increased positively as all the independent variables increase positively with time. All independent variables were found to significantly influence the perception people had about forensic science (Table 4) at the time of study except the age of respondents which explains that younger respondents tend to have positive perceptions about forensic science which is as a result of the correlation between age and their level of education which significantly affected their knowledge about forensic science (Table

5) at the time of the study. Perception about forensic science is a very important aspect of understanding the concept of forensic science (16) as in some cases forensics science has done a great deal of serving social justice (17) while denying others in one way or the other (8) elsewhere.

According to the Encyclopedia of Criminology and Criminal justice, people may derive their conclusive perceptions whether negative or positive based on the outcomes of forensic procedures 
and what they might have heard about forensic science (18). Other people have their perceptions about forensic science which in most cases tends to be positive based on what they normally see on TV and documentaries commonly known as the Crime Scene Investigation (CSI) effect (19), which yields unrealistic expectations. Forensic science has brought tremendous effect to the area of crime-solving but, what most people do not know is that some issues or situations go beyond forensic science. It is no doubt that elsewhere people's perceptions about forensic science are based on unsupported assumptions and exaggerated claims which do not exist anywhere in forensic science.

In Ghana, issues of institutional trust concerning the GPS and the general public has been addressed by (10) and it is considered as very sensitive issue which needs redress. The extent of this sensitivity was felt as respondents were informed about the GPS operating the state's forensic unit. Apparently, the negative sentiments about the GPS is a reality and the issue with poor and under resourced criminal investigations in Ghana has gone beyond institutional trust. The Managing Editor of the Insight Newspaper Kwesi Pratt Jnr proclaims after his office was burgled "With all the unsolved crimes in Ghana what would mine do? I don't want to waste my time...It's not a question of trust, it's a question about track records with investigations if you want I can give you the long list of unsolved crimes..." (20). These situations are not so new in the system as De'lemont mentioned in his work in 2014 that forensic science and crime solving procedures are influenced by many actors which includes physical, intermediate and criminal environments and it is likely that social actors will be involved in the final decision making. It is obvious in (Table 4) that positive perceptions about forensic science can be achieved if the public is positive about the GPS and their operations but the reality on grounds is that others feel that the FSL is going to reflect ineffective services as the GPS is presumed to offer based on respondents point of view. 
All four neighborhoods had respondents who had bad perception about the GPS which significantly affected the negative response they all gave regarding forensics in Ghana.

Forensic knowledge and awareness and perception are significantly influenced by respondents level of education (Table 4,5) and it is very clear and explainable that education tends to expand the faculties $(22,23)$ of individuals. As it stands there is presumably a higher chance of individual respondents coming across information regarding forensic science in their educational journey or as they climb higher the ladder of education because it is no doubt that people's perceptions about a phenomenon can be measured based on their level of education (23).

Another influential factor is that in Ghana, students at the tertiary level are allowed to use mobile phones and laptops to facilitate learning. Based on the fact about the data collected a good number of those who had an idea about forensic science were tertiary students and most of them had their knowledge of forensics science from movies and documentaries. The findings further assert that an improvement in watching crime-related movies and documentary will expose more people to forensic science and forensic procedures. Nonetheless the effectiveness of forensic procedures as informed by (21) is not actually what popular trends on movie series and documentaries present to us but is rather found in literature, crime laboratories and the court of law where the cycle of criminal justice ends.

The respondent's level of education, the state of forensic support, perception about forensics in Ghana, the general perception about GPS, and where respondents obtained their knowledge about forensic were found to have significantly impacted respondent's knowledge, perception, and awareness of forensic support to criminal investigations (Table 4,5). The study described forensic support to criminal investigations as a force that will contribute to the massive reduction of 
numerous blanketed crimes, wrongful convictions and exonerations (25), and emerging and existing crimes such as kidnapping (26), rocketed rate of cybercrime (27), misled court decisions regarding sexual assault (28), the list of unsolved murders (29), and many other crimes in Ghana. Forensic support to criminal investigations significantly influences respondents knowledge about forensics as it is clear from the data (Table 5) but it was more surprising to find respondents who were very much aware of the rate of cybercrime in the country (27) but were clueless about measures of apprehending cyberfraudsters (30) until they were educated about the importance of forensic science in cybercrime and security.

While interviewing respondents, they were probed further for their views on how they see crime solving and the impact of forensic science based on their perspectives. The views came from different angles with religious, cultural, and contemporary perspectives. Comments recorded from respondents include "I would willingly give out my biological sample if I know the purpose". A respondent who was a renowned Islamic scholar at the time of the study also said "our sacred scriptures teach us about serving justice even if it is against ourselves, I do not want to be a part of justice miscarriage because justice denied is an offence. Any authorized personnel from the Ghana Police Service will be allowed to collect my biological data for DNA extraction, analyze it to solve a crime situation, and grant justice". Some respondents were very keen on how cultural beliefs influenced the shaping and direction of their views on crime. A specific comment passed by a respondent was "there should be no compelling reason for me to take such an action because in the first place I will not involve myself in any crime". Others had doubts about the success of forensic operations and claim the professionalism and credibility of practitioners have been greatly affected by political influence in Ghana so how different is forensic science? (31) assert that for 
the general populace to get a better understanding of forensics science, then the elementary actions of investigation and processing of evidence as well as judicial processes must be improved.

\section{Forensic science as an effective tool to achieve sustainable development goal}

Sustainable development goal (SDG) 16 promotes democratic governance for peace, security and rule of law, protection of fundamental human rights and inclusive societies and it has a link with all SDGs and it is a vital precursor for economic development (32). The findings of the study show that there are millions of vulnerable people in Ghana who have been denied their fundamental human rights simply because of wrongful convictions and investigations and lack of resources for the investigation of sophisticated crimes (33).

Over the years there have been a very poor relationship between delivering justice and solving crimes such as burglary, cybercrime corruption, document fraud, murder, sexual and physical assault, familial and litigious issues even though Ghana's adversarial system has adopted forensic science in their mode of operation. Real perpetrators of crime mostly are allowed to walk on the streets of Ghana freely because of inadequate resources or substantial evidence to put them to justice (12-14) and that tends to put the next innocent victims at risk. The daunting effect of this poor system is seen in the underdevelopment occurring in various sectors of the state's economic growth and progress even though strides and prudent measures are being implemented continuously.

The recent spike in crime rate is more likely to be attributed to the poor criminal justice system in the future if profound measures are not adopted to curb crimes in Ghana. As Ghana intends to achieve SDG 16, it is imperative to enforce forensic science which is globally known as an 
effective tool for justice delivery (34). The burden of social justice should not be forgotten hence people involved in criminal activities should be brought to justice.

\section{CONCLUSION}

In conclusion, the cost of security might be overwhelming outrageous in a developing country like Ghana and it might not seem so easy shifting from the old methods of doing things, however, it is worth spending more Ghana cedis on improving forensic science if we still believe in the fundamentals of freedom and justice. Based on the findings of this study, the state of forensics in Ghana is deplorable and that may present peculiar difficulties in the future looking at the unpredictable increase of crime rate in the country. Crime in Ghana nowadays are being committed through sophisticated ways and the study makes it obvious that if perpetrators of such crimes are not identified and brought to justice through sophisticated technology such as forensic science then they are being rewarded because they will always get away with crimes easily.

The study identified the lack of awareness of forensic science amongst the Ghanaian population including the elite and non-elite of the society and more fascinatingly, some security personnel notably private security guards and Motto Traffic \& Transport Department (MTTD) of the GPS. The study mentions that education is a vital precursor of knowledge acquisition and it must be leveraged to tackle the issue of advocacy and awareness about forensics in the country.

The study makes it clear that as part of maintaining law and order, forensic science must be used to curb impunity in Ghana so that criminals will know that they cannot commit a crime and go free. Practically, the findings of this study can serve as springboards for the Government of Ghana and respective stakeholders to make improvements in forensics, general policing practices and 
strategies to protect the lives of people and ensure that justice is served because the opportunity cost of not investing in forensics is real and significant.

\section{POLICY RECOMMENDATION}

It is paramount that the Government of Ghana, GPS, and all respective stakeholders should consider their involvement in ensuring national security is key hence the study recommends firstly that law and order must be heavily enforced in Ghana. Similar comparative and relative studies must be conducted in different regions of the country to update the general populace about the status quo of forensic support to criminal investigations. The recidivism effect is very real hence, the creation of specific forensic databases will be a great step to identify and apprehend perpetrators of specific crimes with hopes of a national database in the future. Funding of forensic research, offering scholarships and academic grants to students interested in forensic careers, the establishment of forensic education and outreach programs, instituting a government recognized forensic society of Ghana, and media advocacy are excellent suggestions for a progressive change in the area of forensic science in Ghana.

The inclusion of aspects of forensic science in the educational curriculum from basic school to the higher-level education of Ghana will enhance the awareness and knowledge about forensic science. Hospitals and research laboratories that are of a good standard must be refurbished and equipped with resources that will aid in forensic analysis to serve as a means to fast-track forensic operations and minimize case backlog due to the overreliance on only one forensic laboratory. Ghana needs a local forensic science and criminology institution to groom people interested in crime-solving careers with both local and exotic crime-solving techniques to help solve crime in our Ghanaian setting and beyond. Furthermore, the establishment of forensics programs in more 
of Ghana's tertiary institutions will not only be a cutting-edge innovation but as a problem-solving initiative by increasing the number of forensic expertise nationwide. The Ministry of Interior should make efforts to maximize the autonomy within the GPS and FSL with the call for an independent forensic science department in Ghana being considered as a major priority. Forensic science should be considered as a priority because a nation without peace and justice institutions, human rights, and effective governance through the rule of law cannot boast of proper security, sustainability, and prosperity. 


\section{REFERENCE}

1. Chief Scientific Adviser. Annual Report of the Government Chief Scientific Adviser 2015: Forensic Science and Beyond: Authenticity, Provenance, and Assurance. Evidence and Case Studies. 2015; Accessed on (September 2019). Available from: https://www.gov.uk/government/publications/forensic-science-and-beyond

2. Science and Technology Select Committee. Forensic science and the criminal justice system: a blueprint for change. 3rd Report of Session 2017-19. 2019. Accessed on (September 2019). Available from:

https://publications.parliament.uk/pa/ld201719/ldselect/ldsctech/333/33302.htm

3. Crispino F, Houck MM. Principles of Forensic Science. In: Encyclopedia of Forensic Sciences: Second Edition. 2013. Accessed on (July 2018) Available from: https://www.sciencedirect.com/referencework/9780123821669/encyclopedia-of-forensic$\underline{\text { sciences\#book-info }}$

4. Aning EK. An overview of the Ghana police service. Journal of Security Sect. Managment. 2006;4(2):1-37. Accessed on (November 2019). Available from: https://www.researchgate.net/publication/237724689_An_Overview_Of_The_Ghana_Poli $\underline{\text { ce_Service/stats }}$

5. Wikipedia. Ghana Police Service. 2019; Accessed on (September 2019) Available from: https://en.wikipedia.org/wiki/Ghana_Police_Service 
6. Amankwaa A. History of forensic science in Ghana-overview. Vol. 1, Scientect e-mag. 2016. A1 p. Accessed on (June 2018). Available from:

https://www.researchgate.net/publication/319112929_History_of_forensic_science_in_Gh ana-overview

7. GPS. Forensic Science Laboratory [Internet]. 2017. Accessed on (June 2019). Available from: http://police.gov.gh/forensic-science-laboratory---fsl.html

8. Amankwaa AO, Nsiah Amoako E, Mensah Bonsu DO, Banyeh M. Forensic science in Ghana: A review. Forensic Sci Int Synerg. 2019; Accessed on (June 2018). Available from: https://doi.org/10.1016/j.fsisyn.2019.07.008

9. Mensah RO. Assessment of Training Practices in the Ghana Police Service. Journal Of Law Policy And Globalization. 2018;79:265-73. Accessed on (December 2018). Available from: https://www.iiste.org/Journals/index.php/JLPG/article/view/45409

10. Boateng FD. Institutional trust and performance: A study of the police in Ghana. Australian and New Zealand Journal of Criminology. 2018;51(2):164-82. Accessed on (June 2018). Available from: https://doi.org/10.1177/0004865817712335

11. Rono L. Microcredit and its relationship to the growth of small and medium enterprises in Konoin Subcounty, Kenya. International Journal of Advanced Research. 2018; 6(4), 961968. Accessed on (May 2019). Available from: http://dx.doi.org/10.21474/IJAR01/6935

12 Africa's-Greatest-Unsolved-Murders-3 [Internet]. Accessed on (September 2019). Available from: https://kweiquartey.com/africas-greatest-unsolved-murders-3-2/ 
13. 5 High-Profile Murder Cases Ghana Police have no Answers to [Internet]. Accessed on (September 2019). Available from: https://yen.com.gh/144479-5-unresolved-high-profilemurder-cases-ghana.html

14. 2019 in Review: High profile murders of 2019 [Internet]. Accessed on (September 2019).. Available from: https://www.ghanaweb.com/GhanaHomePage/NewsArchive/2019-inReview-High-profile-murders-of-2019-823297

15. Chapter 9 Survey Research | Research Methods for the Social Sciences [Internet]. Accessed on (May 2018). Available from: https://courses.lumenlearning.com/suny-hcccresearch-methods/chapter/chapter-9-survey-research/

16. Edmond G, Towler A, Growns B, et al. Thinking forensics: Cognitive science for forensic practitioners. Sci Justice. 2017;57(2):144-154. Accessed on (June 2018). Available from: doi:10.1016/j.scijus.2016.11.005

17. Claude Roux, Frank Crispino \& Olivier Ribaux. From Forensics to Forensic Science, Current Issues in Criminal Justice, 24:1, 724. Accessed on (June 2018). Available from: doi: $\underline{10.1080 / 10345329.2012 .12035941}$

18. Cole S.A. Forensic Science and Miscarriages of Justice. In: Bruinsma G., Weisburd D. (eds) Encyclopedia of Criminology and Criminal Justice. Springer, New York, NY. 2014. https://doi.org/10.1007/978-1-4614-5690-2_233

19. Cole, Simon A and Glenn Porter, "The CSI effect" in The Routledge International Handbook of Forensic Interlligence and Criminology ed. Quentin Rossy, David De'caryHetu, Olivier Dele'mont and Massimiliano Mulone (Abingdon: Routledge, 08 Dec 2017), 
Accessed on (Augurst 2018). Available from:

https://www.routledgehandbooks.com/doi/10.4324/9781315541945-10

20. Pratt cites high unresolved crimes as reason for not involving police in office burglary [Internet]. Accessed on (Augurst 2020). Available from: https://www.ghanaweb.com/GhanaHomePage/NewsArchive/Pratt-cites-high-unresolvedcrimes-as-reason-for-not-involving-police-in-office-burglary-1036744

21. Delémont O., Lock E., Ribaux O. Forensic Science and Criminal Investigation. In: Bruinsma G., Weisburd D. (eds) Encyclopedia of Criminology and Criminal Justice. Springer, New York, NY. 2014. https://doi.org/10.1007/978-1-4614-5690-2_145

22. Lochner, Lance, "Nonproduction Benefits of Education: Crime, Health, and Good Citizenship," in E. Hanushek, S. Machin, and L. Woessmann (eds.), Handbook of the Economics of Education, Vol. 4, Ch. 2, Amsterdam: Elsevier Science, 2011.

23. The wellbeing effect of education - Economic and Social Research Council [Internet]. Accessed: Sep 2019. Available from: https://esrc.ukri.org/news-events-andpublications/evidence-briefings/the-wellbeing-effect-of-education/

24. Forensic Science and Criminal Inquiry. In: Bruinsma G., Weisburd D. (eds) Encyclopedia of Criminology and Criminal Justice. Springer, New York, NY. 2014. https://doi.org/10.1007/978-1-4614-5690-2_100264

25. Eric Asante Vrs Republic (J8A/03/2017) [2018] GHASC 33 (30 May 2018); | Ghana Legal Information Institute [Internet]. 2017; Accessed on (December 2018). Available from: https://ghalii.org/gh/judgment/supreme-court/2018/33 
26. Yahaya SS. Kidnapping in Ghana : an emerging crisis ? Scientect E-mag. 2019 Issue. Accessed on (November 2019). Available from: https://fssgh.org/2019/12/06/kidnappingin-ghana-an-emerging-crisis-scientect/

27. Warner J. Warner-Understanding Cyber-Crime in Ghana: A View from Below Under a creative commons Attribution-Noncommercial-Share Alike 2.5 India License 736 Understanding Cyber-Crime in Ghana: A View from Below. International Journal of Cyber Criminology. 2011. Accessed on (June 2019). Available from: https://www.cybercrimejournal.com/warner2011ijcc.pdf

28. Kpebu v Attorney General (J1/8/2016) [2016] GHASC 26 (05 December 2016); | Ghana Legal Information Institute [Internet]. 2016; Accessed on (September 2019). Available from: https://ghalii.org/gh/judgment/supreme-court/2016/26

29. Adinkrah M. Homicide-suicide in Ghana: perpetrators, victims, and incidence characteristics. International Journal of Offender Therapy and Comparative Criminology. 2014;58(3):364-387. Accessed on (December 2018). Aavailable from:doi:10.1177/0306624X12470530.

30. Baylon C, Antwi-boasiako A. Increasing Internet Connectivity While Combatting Cybercrime: Ghana as a Case Study. 2016;(44). Accessed on (June 2018). Available from: https://www.cigionline.org/publications/increasing-internet-connectivity-whilecombatting-cybercrime-ghana-case-study

31. Hazard D., Margot P. Forensic Science Culture. In: Bruinsma G., Weisburd D. (eds) Encyclopedia of Criminology and Criminal Justice. Springer, New York, NY. 2014. 
https://doi.org/10.1007/978-1-4614-5690-2_148

32. Malone DM. On SDG 16: Peace, Justice, and Strong Institutions. Free from Fear. 2018; Accessed on (July 2019). Available from: https://ourworld.unu.edu/en/sdg-16-peacejustice-and-strong-institutions

33. Odartey-Wellington F, Alhassan A, MacRae S. 'Newsworthy victims': The killing of Maxwell Mahama and the culture of lynching in Ghana. Journal of Applied Journalism \& Media Studies. Accessed on (June 2020). Available from: https://www.researchgate.net/publication/340404367_\%27Newsworthy_victims\%27_The _killing_of_Maxwell_Mahama_and_the_culture_of_lynching_in_Ghana

34. Yahaya SS. Achieving SDG 16 in Ghana: The role of forensic science [Internet]. Scientect E-mag. Forensics. Accessed on (September 2020). Available from: https://www.researchgate.net/publication/343944304_Achieving_SDG_16_in_Ghana_the _role_of_forensic_science 